\title{
3D CULTURAL HERITAGE DOCUMENTATION: A COMPARISON BETWEEN DIFFERENT PHOTOGRAMMETRIC SOFTWARE AND THEIR PRODUCTS
}

\author{
S. Gagliolo ${ }^{\text {a }}$, E. Ausonio ${ }^{\text {a }}$ B. Federicia ${ }^{\text {, I. Ferrando }}{ }^{\text {a }}$, D. Passonia ${ }^{\text {a D. Dguerso }}{ }^{\text {a }}$

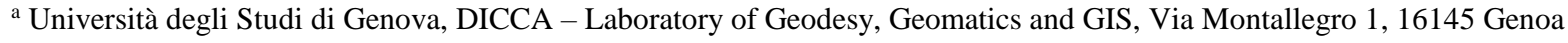 \\ (sara.gagliolo, ilaria.ferrando)@edu.unige.it, elena.ausonio@hotmail.it, daniele.passoni@dicca.unige.it, \\ (bianca.federici, domenico.sguerso)@unige.it
}

Commission II, WG II/8

KEY WORDS: Cultural Heritage, Data Repositories, Emergency, Photogrammetric workflow,
Photogrammetric software comparison, Dense cloud validation, Terrestrial Laser Scanner

\begin{abstract}
:
The conservation of Cultural Heritage depends on the availability of means and resources and, consequently, on the possibility to make effective operations of data acquisition. In facts, on the one hand the creation of data repositories allows the description of the present state-of-art, in order to preserve the testimonial value and to permit the fruition. On the other hand, data acquisition grants a metrical knowledge, which is particularly useful for a direct restoration of the surveyed objects, through the analysis of their 3D digital models. In the last decades, the continuous increase and improvement of 3D survey techniques and of tools for the geometric and digital data management have represented a great support to the development of documentary activities. In particular, Photogrammetry is a survey technique highly appropriate in the creation of data repositories in the field of Cultural Heritage, thanks to its advantages of cheapness, flexibility, speed, and the opportunity to ensure the operators' safety in hazardous areas too. In order to obtain a complete documentation, the high precision of the on-site operations must be coupled with an effective post-processing phase. Hence, a comparison among some of the photogrammetric software currently available was performed by the authors, with a particular attention to the workflow completeness and the final products quality.
\end{abstract}

\section{INTRODUCTION}

The conservation of Cultural Heritage is a fundamental and very demanding task, which requires the employment of many means and resources. The existence of a huge number of works of art makes the choice of an adequate strategy of data acquisition, distribution and fruition even more important, in order to reach two different objectives: the documentation and, if needed and possible, the restoration. The ultimate objective of these activities is to avoid the decline of material goods belonging to Cultural Heritage in order to preserve their artistic, historical and testimonial values.

Photogrammetry and Terrestrial Laser Scanning (TLS) are techniques for 3D metrical reconstruction widely employed. Depending on the final awaited results, the available time, the conditions of the surveying object and the economic resources, Photogrammetry can represent a valid alternative or a beneficial ally of TLS, which has a higher cost and is not always light and easy to handle. Both techniques need an accurate planning to satisfy the required precision, concerning number and location of scans for TLS and number and orientation of images for Photogrammetry. The main advantage of Laser Scanning technique is the direct production of point clouds describing the object or the scene, while in the photogrammetric approach a substantial post-processing phase is mandatory to build the point cloud starting from images. The resolution of the TLS point cloud depends on the angular resolution of the instrument and on the distance from the surveyed surface, while the resolution of the photogrammetric point cloud depends on the dimension of the image pixel projected on the surface, and on the quality level achievable by the different software employed for the processing. During the survey and the post-processing phases, an improving of the resolution level leads to dilate the operative times; thus, it is important to take care of the planning and of the set-up parameters, when quick results are required.

In the present work, the performance of the post-processing phase obtained by means of dedicated photogrammetric software is examined in depth, in order to build a final $3 \mathrm{D}$ model.

Several software, both commercial and Open Source (OS), have been evaluated: Agisoft PhotoScan $\odot$ v. 1.2.6 (Agisoft PhotoScan@, 2018), Pix4Dmapper@ v. 4.1.25 (Pix4D@, 2018), ContextCapture $^{\mathrm{TM}}$ v. 4.4.7.68 (ContextCapture, 2018), VisualSFM v. 0.5.25 (VisualSFM, 2018), insight3d 0.3.2 (insight3d, 2018), MicMac v. 1.0.beta11 (MicMac, 2018).

The tests have been performed by means of a list of pre-set parameters and has been applied at the case study of the Castle of Casalbagliano (Alessandria, Italy).

Since the authors have a moderate experience in the use of Agisoft PhotoScan $\odot$, while they are not experienced users with respect to the other software, and since a complete test has been already performed for the specific case study with Agisoft PhotoScan $\odot$, giving reliable results, these are taken as reference in the comparisons with the other software. Then, a comparison with a TLS point cloud was performed too.

The development of the contents is organised as described in the following. In Section 2, the state of the art on photogrammetric software comparison is shown, with particular attention to the variety of case studies taken into account. In Section 3, the selection of the image datasets and the choice of the parameters of comparison is explained. In Section 4, each software is individually described with respect to the performed tests. In Section 5, a comparison of the photogrammetric point clouds, obtained during the tests, against the TLS point cloud, 
used as reference, is performed. Finally, Section 6 summarizes the main results.

\section{STATE OF THE ART ON PHOTOGRAMMETRIC SOFTWARE COMPARISON}

The theme of photogrammetric software comparison has been widely developed and discussed by several authors, deepening different aspects and treating a wide selection of case studies. This topic is so intensely examined because of the large number of existing software with their specific parameters, the several fields of application, and the different obtainable products, in addition to the continuous update and improvement of the available technologies.

The innovations in the field of Photogrammetry, concerning matching algorithms and quality of digital airborne cameras, have led to a substantial increase of the quality of 3D models obtained by images. An analysis of the state of the art in airborne image matching is performed in the joint ISPRF/EuroSDR project "Benchmark on High Density Aerial Image Matching" (Haala et al., 2016) with a special focus on high quality geometric data captured in urban scenarios.

In the specific field of Cultural Heritage, several authors have considered as case studies both large and small scale entities, such as historical sites (e.g. the City of Harireh, Iran, in Alidoost et al., 2017, or Stonehenge in Wojtas, 2010) or archaeological objects (Pavelka et al., 2013), to test and evaluate the performance of photogrammetric software.

With the same purpose, other researchers focus on environmental and naturalistic scenarios, such as: the Coral Reef (Burns et al., 2017), to represent and quantify the intricate structural complexity of corals; a vegetated rock face (Niederheiser et al., 2016), to discern various thematic areas, i.e. nude rock and vegetation; a forest (Svensk, 2017), to keep track of the growing conditions. In Gini et al. (2013), focused on the case study of Parco Adda Nord, this theme has been developed by one of the authors of the present paper. Meanwhile, significant changes have been applied to the analysed software, hence also this author could be considered as a not experienced user.

Another approach to the comparison considers the study of several datasets relative to objects of different complexity and scale, in which different significant parameters change, such as, mainly, the number of images and the cameras positions with respect to the scene (Remondino et al., 2014, Schöning et al., 2015).

Additionally, Gabara et al. (2017) focuses the attention on the reproduction of particular inconvenient conditions, such as: small, flat, elongated and horizontally oriented close range object; disadvantageous configuration of photos; control points located approximately on a plane; use of non-metric, mediumresolution digital single-lens reflex camera; difficult geometric and radiometric conditions of digital multi image matching.

Lastly, some authors focus only on a specific output, i.e. point cloud, mesh or orthophoto, and do not consider the whole procedure of the examined software (e.g. orthophotos in Haala, 2013).

The present work is meant as a complete analysis of the software workflow, with particular attention to the final quality of the dense point clouds, taking into account three datasets of the same object, represented by a building of the Italian Cultural Heritage.

\section{DATASETS DESCRIPTION AND TLS REFERENCE POINT CLOUD}

As already mentioned, the analysed case study is the Castle of Casalbagliano in Alessandria (Italy).

The building dates back to the XIII century, as inferable from its square map and from the construction techniques employed. A tower about 30 meters high stands out on the East side of the Castle; it is the only portion safeguarded by the Soprintendenza Belle Arti e Paesaggio della Provincia di Alessandria.

The whole structure is currently in a bad, obsolete and neglected state of repair, because of both the catastrophic flood of Tanaro River (1994) and the abundant invasive spontaneous vegetation.

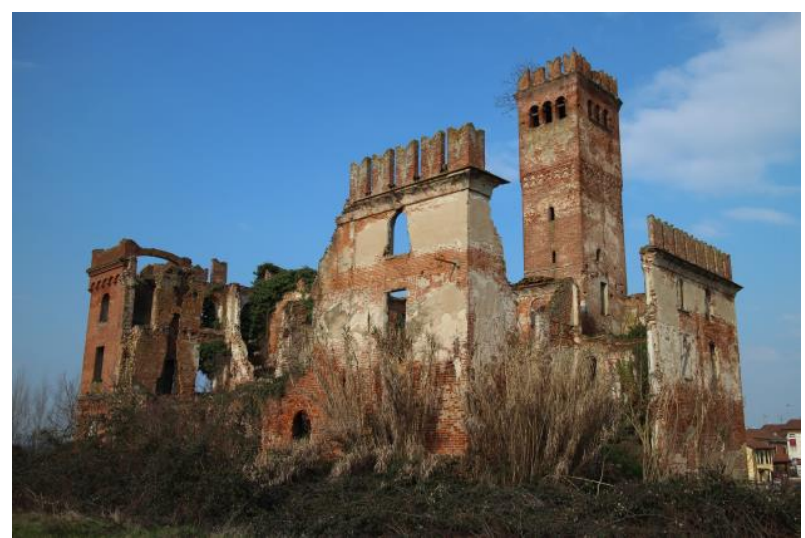

Figure 1. A view of the present condition of the Castle of Casalbagliano.

\subsection{Photogrammetric datasets}

Three different datasets, corresponding likewise to three acquisition geometries, have been considered. They have been acquired using the Canon EOS-M camera, with a fixed focal distance of $22 \mathrm{~mm}$. The first dataset was obtained by a terrestrial photogrammetric block (referred as T), composed by 28 frames. In the other two datasets the camera was installed on an Unmanned Aerial Vehicle (UAV), a Microcopter hexacopter; the former dataset had a nadiral point of view (referred as $\mathrm{N}$ ) and was composed by 83 frames, the latter was oriented with a tilt angle of $45^{\circ}$ (referred as O) and composed by 61 frames, as shown in Figure 2 Figure 3.

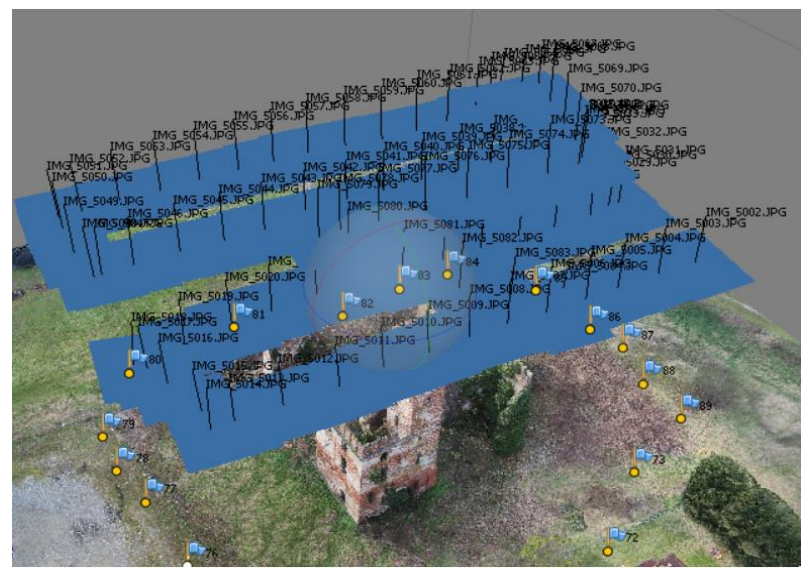

Figure 2. Configuration of the shot geometry of the nadiral dataset 




Figure 3. Camera locations for the oblique photogrammetric block

The taken frames pertain a square area with a side of about 60 $\mathrm{m}$, with the Castle located in the centre; the resulting Ground Sample Distance (GSD) is about $0.01 \mathrm{~m}$.

The images have been georeferenced by means of 19 square targets, whose coordinates have been surveyed with the Total Station (TS) in a local Reference Frame (RF).

The used TS, i.e. Leica Nova Multistation MS60, is characterized by an angular accuracy of $3^{\mathrm{cc}}$ and by a distance accuracy of $1 \mathrm{~mm}+1.5 \mathrm{ppm}$ using reflective prism (Fagandini et al., 2017).

\subsection{TLS datasets}

Concerning the TLS survey, performed using Z+F Imager ${ }^{\circledR}$ $5006 \mathrm{~h}$, eight scans have been taken in order to validate the photogrammetric point clouds. The scans positions have been located around the whole structure at a distance of about 30-40 $\mathrm{m}$ from it. A resolution setting of 20,000 points $/ 360^{\circ}$ has been used to guarantee a spacing of about $0.01 \mathrm{~m}$ in the acquired point clouds. The manufacturer specifies a value of $1.5 \mathrm{~mm}$ root mean square (rms) as measurement noise of the instrument, considering a reflectivity of the surveyed surface of about $20 \%$ and a distance of $25 \mathrm{~m}$.

Additional 32 TLS targets have been surveyed to allow the georeferencing in the same local RF of the photogrammetric point clouds.

The complete description of the survey campaign is included in the paper by Gagliolo et al. (2017).

\section{SOFTWARE ANALYSIS}

The photogrammetric software listed above are analysed and evaluated singularly, paying particular attention to: (1) the possibility to integrate several datasets of images taken by different points of view and eventually with different focal distances, (2) the behaviour in presence of Ground Control Points (GCPs), (3) the speed of calculation, (4) the userfriendliness and completeness of the workflow, (5) the interoperability with external software and platforms, (6) the entity of user communities, (7) the availability of documentation, tutorials and direct support, and (8) the cost. Then a final resume is done to formulate a global opinion.

Instead, the evaluation of the quality of the final products of each software is treated in Section 5, by a comparison with the TLS point cloud.

Although it is possible to fully reconstruct the whole structure only using the $\mathrm{O}$ dataset, the ensemble of images $(\mathrm{T}+\mathrm{N}+\mathrm{O})$ has been processed by the tested software in order to analyse their behaviour dealing with different attitudes. Instead, only the $\mathrm{O}$ dataset has been used for the complete workflow, i.e. internal orientation (IO), external orientation (EO), dense cloud generation, mesh reconstruction, orthophoto production. The $\mathrm{N}$ and $\mathrm{T}$ images have not been included in the complete processing to speed up the elaboration times; moreover, they do not give individually a complete view of the object, because they focus on a preferential portion (roofs and façades, respectively).

All the phases of the workflow are performed using a medium quality, corresponding to a downsampling factor of 4 with respect to the original images.

The analysis discussed have been performed using a desktop Personal Computer (64 bits Windows 7 operating system, Intel ${ }^{\circledR}$ core $^{\mathrm{TM}}$ i7-4770 CPU @ $340 \mathrm{GHz}$ processor and $32 \mathrm{~GB}$ of RAM, Intel@ HD Graphics 4600, 20 Cores @ 400 MHz, 1297 MB).

\subsection{Agisoft PhotoScan $\odot$}

As already mentioned, Agisoft PhotoScan $\odot$ is taken into account as reference, because either the authors have a moderate experience in its use and the obtained results come across as reliable in several contexts.

Several tests have been already performed in a previous work (Gagliolo et al., 2017), with the software version 1.2.6 Professional. From the authors experience, in the latest released version 1.4.1 no significant changes have been made with respect to the analysed parameters; thus, the tests were not repeated.

The software is characterized by a complete workflow. It succeeds in the alignment of both the images configurations: the single oblique dataset and the $\mathrm{T}+\mathrm{N}+\mathrm{O}$ ensemble.

The computation time of the alignment phase and the dense cloud reconstruction of the $\mathrm{O}$ dataset are 30 minutes and 1 hour and 15 minutes, respectively.

The GCPs picking is available. It is also possible to activate an automatic research of the GCPs when the operator has manually inserted at least three projections.

The interface is user-friendly and the structure of the workflow is clear for an unexperienced operator. In the dropdown list called workflow, the different phases are active only when the previous steps are processed, suggesting the correct sequence of commands and providing a logical order.

The interoperability is guaranteed by the possibility to choose many different file formats to export all the obtainable products. On the web site, there is a community section, including showcases, articles, blog and forum, and a support section, including tutorials, tips, FAQ and a contact form. The software is widely diffused because of the ease-of-use and the lower cost than other commercial software. The program is also available with an educational license, reserved to schools and universities.

\subsection{Pix4D $\subset$}

Pix4D@ is a widely used commercial software. Its diffusion is due to the cooperation with consortia for the UAV production and to the existence of multiple specific solutions dedicated to mapping, mining, forensic and public safety. The tested version is the mapping one.

The alignment performed using three datasets $(\mathrm{T}+\mathrm{N}+\mathrm{O})$ didn't succeed: only 126 of 172 photos have been oriented, the terrestrial dataset and two sides of the oblique one have been ignored. To avoid this behaviour, it is recommended to treat the different datasets separately, considering them in homogeneous chunks, and to add GCPs.

During the alignment phase performed only on the oblique dataset, it was not possible to reconstruct the whole structure, 
but only two adjacent sides at a time. This could be due to the particular oblique configuration of images. In facts, the software optimally works in its standard conditions, such as nadiral geometry, fisheye lens and in presence of a telemetry.

The time needed for the processing was about 30 minutes for the alignment phase, 1 hour and 30 minutes for the dense cloud reconstruction.

A tool is available to pick the GCPs on the images. As previously introduced for Agisoft PhotoScan $\odot$, an automatic procedure allows to speed up this operation.

Concerning the completeness of the workflow, all the analysed phases are available in this software. Typically, the interaction with the workflow to modify the default settings is not so simple and intuitive for the unexperienced operator, in spite of the user-friendliness of the user interface.

The number of output file formats is limited to four for the dense cloud and five for the mesh. The user could select multiple file format at a time, but the choice must be done before the launch of the processing.

The software web site is equipped with an official and interactive support, both from the user community and from the developers, by means of articles, forum posts or mail; there are also a tutorial section and a blog with latest news and events.

The cost of the perpetual license of the tested version is about twice the price of Agisoft PhotoScan $\odot$. It is available an educational version, cheaper than the stand-alone one, reserved to schools and universities.

\subsection{ContextCapture ${ }^{\mathrm{TM}}$}

ContextCapture ${ }^{\mathrm{TM}}$ is a commercial software belonging to the Bentley group. The tests on this program have underlined good performances.

The software manages the processing of the alignment, both on the oblique dataset and on the $\mathrm{T}+\mathrm{N}+\mathrm{O}$ ensemble. The speed of calculation for the $\mathrm{O}$ alignment and the related dense cloud production has been the shortest of the evaluated software, needing approximately 5 and 20 minutes, respectively.

The medium quality for the Aero Triangulation (AT) has been obtained applying a downsampling $(50 \%)$ on the images.

GCPs could be picked thanks to a dedicated interface, but the pointer which identifies each picked point hasn't a label with the ID number. As already said for the other commercial software, when the operator has placed the minimum number of point projections in the images, the other points could be detected by the software itself by re-launching the AT. Then the operator can validate the locations and eventually fix them.

Some problems have been observed fixing the RF before the point cloud elaboration: the produced cloud has a very higher number of points, characterized by incorrect positions; it generates a significant noise, hence the structure results affected by deformations. If the elaboration is performed without the referencing, the point cloud includes a reasonable number of points and without noise. Nevertheless, the authors are confident that a skilled user could remove this noise by conveniently modifying the default settings and keeping the GCPs activated.

To allow the comparison with TLS cloud, the RF is conferred using the tool available in CloudCompare v. 2.8.1 (CloudCompare, 2018).

The structure of the workflow is intuitive, in facts the phases could be processed only following their logical order. There is a significant difference in the workflow with respect to the other software analysed: after the AT, the point clouds, mesh and orthophotos could be reconstructed autonomously.
The interoperability is not a strong point of this software, which allows the export the point clouds only in two file formats (LAS and POD); conversely, there is a higher variety for the mesh export, but many formats are not so diffused. Moreover, the file format must be decided before the processing and multiple selections are not allowed.

Regarding the web documentation, on-line support, videotutorials, overviews on the current works shared by other users are available.

The cost of the software package, including other strictly related programs, is more than twice the price of Agisoft PhotoScan $\odot$. Also in this case, it is possible to obtain an educational version, which is free for an year, then is available for a special fee.

\subsection{VisualSFM}

VisualSFM is a free but not OS software. In authors opinion, the interface is its weak point: the commands present different names if selected from the dropdown menus or from the shortcuts; some important tools are not clearly underlined, some others must be used in specific views which aren't set automatically. For example, the key needed to save projects and the function to modify the quality of outputs are not pointed out.

Nevertheless, the software has been able to process the alignment, divided in several steps, both on the oblique dataset and on the $\mathrm{T}+\mathrm{N}+\mathrm{O}$ ensemble.

The speed of calculation for the various steps of the alignment phase and for the dense cloud reconstruction, both performed on the oblique dataset, has been respectively of 10 and 50 minutes.

An interface to pick GCPs is available, but, as in ContextCapture $^{\mathrm{TM}}$, there ID is not shown clearly near each picked point. Moreover, photos visualization is not clear as expected in order to perform a good point picking. It is possible that a downsampling is automatically applied on the images, without any message to the user. About the RF, note that, differently from the other tested software, the $\mathrm{Z}$ coordinate is intended as a planimetric component, instead of a vertical one as it is typically intended.

As in ContextCapture ${ }^{\mathrm{TM}}$, some problems have been observed giving the RF: the cloud produced is well reconstructed in the grass around the Castle, where the GCPs are located, but the structure is affected by significant holes. Without the referencing, the entire point cloud is built successfully. To allow the comparison with TLS cloud, the RF is conferred using the tool available in CloudCompare.

The workflow is not complete, in fact mesh and orthophotos are not directly obtainable. However, for the mesh reconstruction, an external tool is available.

Concerning the interoperability, the point cloud could be exported using only the PLY format.

Tutorials, documentation and support are available on the web.

\section{5 insight3d}

insight $3 \mathrm{~d}$ is a free and OS software. The workflow of the tested version, installed using binaries on Windows, is only limited to the alignment phase, that includes the point matching, the IO and EO computation, and lastly the sparse cloud realization. The other phases, including GCPs picking, are not available. The software is not suited at all to align photos from different points of view. Moreover, in the alignment of the single oblique dataset, it crashed trying to process the whole group. Nevertheless, in order to give information about the operative 
principles, a group of 10 photos from the oblique dataset has been processed.

The interface is not much user-friendly, in facts an unexperienced operator could not easily understand how to interact with the software menus.

Several reports are available to be exported and used as inputs in other external programs, according to the principle of interoperability.

The development of the software is going forward for a compiled version in Linux, thanks to a small user community. The main developer is available to give support if needed. The documentation is limited to a single tutorial file in pdf format.

The obtained sparse cloud represents the Castle quite well, but the lacks of the software workflow and the impossibility to use the whole dataset make the inclusion of insight $3 \mathrm{~d}$ not significant for the following comparison. To process the limited number of images, the speed of calculation is good, but obviously this parameter is not comparable with the performance of the other software.

\subsection{MicMac}

MicMac is a widely diffused free and OS software. It is known for its rigorous approach, which is often reflected in a long time of calculation.

The software succeeded in processing both the only oblique dataset and the $\mathrm{T}+\mathrm{N}+\mathrm{O}$ ensemble. However, the alignment of the three datasets, obtainable with the combination of Tapas, Tapioca, and Apero tools, needed even 12 hours to be completed.

Concerning the speed of processing of the oblique dataset, considered for the comparison, the modules for AT have been performed in 50 minutes, while the point cloud reconstruction has required about 40 minutes.

The standard release of MicMac does not provide for a graphical interface, in facts it is a command-line software. However, some dedicated visualization tools have been developed on demand, to process specific phases and not the whole workflow. The only phase which could rely on its own interface is the GCPs picking (SaisieAppuisInit module). However, this is not much intuitive and, whenever it is opened (e.g. to add a new point), all the previously picked points must be revalidated one by one, wasting time.

The results in terms of RMSE are very different from the other software; this behaviour can be explained because the criterion used is the rigid registration and not the adjustment.

The dense point cloud, obtainable with the $C 3 D C$ tool, could be preceded by several pre-set procedures (Ground, Statue, Forest, TestIGN, QuickMac, MicMac, BigMac, MTDTmp), which are ready-to-use in specific conditions (e.g Forest is appropriate to process images of vegetation).

It seems that the only available point cloud file format is PLY.

In spite of the Wiki and the tutorials available, the usage is not simple, starting from the installation process. From the authors experience, the first attempts of tests have been affected by continuous problems and errors, and then further attempts have been repeated many times.

The workflow is complete, but the internal tool for the mesh reconstruction is not recommended by the users in the forum.

\subsection{Summary comparison}

The main features of the analysed photogrammetric software are summarized and compared in Table 1, with particular attention to the parameters introduced at the beginning of Section 4 .

\begin{tabular}{|c|c|c|c|c|c|c|}
\hline & 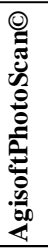 & $\stackrel{\ominus}{\stackrel{7}{*}}$ & 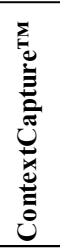 & 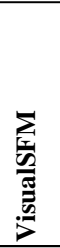 &  & 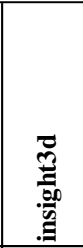 \\
\hline License & $\mathrm{P}$ & $\mathrm{P}$ & $\mathrm{P}$ & F & $\mathrm{F}-\mathrm{OS}$ & F- OS \\
\hline Time & $\circ$ & $>$ & $\ll<$ & $\ll$ & $<$ & $x$ \\
\hline $\begin{array}{l}\text { Integration of } \\
\text { datasets }\end{array}$ & $\checkmark$ & $x$ & $\checkmark$ & $x$ & $\checkmark$ & $x$ \\
\hline GCPs input & $\checkmark$ & $\checkmark$ & $\checkmark$ & $\checkmark$ & $\checkmark$ & $x$ \\
\hline User-friendliness & $\circ$ & $=$ & $=$ & $<$ & $\ll$ & $<$ \\
\hline Workflow & $\circ$ & $=$ & $=$ & $<$ & $=$ & $\ll<$ \\
\hline Inte rope rability & $\circ$ & $<$ & $<$ & $<$ & $<$ & $\ll<$ \\
\hline User communities & $\circ$ & $=$ & $<$ & $<$ & $=$ & $\ll<$ \\
\hline $\begin{array}{l}\text { Documentation, } \\
\text { tutorials and direct } \\
\text { support }\end{array}$ & $\circ$ & $=$ & $=$ & $\ll$ & $=$ & $\ll<$ \\
\hline $\begin{array}{l}\text { Cost (compared } \\
\text { with Agisoft } \\
\text { Photoscan } \odot \text { ) }\end{array}$ & $\mathrm{n}$ & $2 n$ & $>2 n$ & 0 & 0 & 0 \\
\hline
\end{tabular}

Legend

P: Proprietary; F: Free; OS: Open Source;

$\circ:$ used as reference; $\checkmark$ : present; $X$ : absent;

$<,<<,<<<$ : minor (increasing levels);

$>\rangle\rangle,\rangle>>$ : major (increasing levels);

$=:$ equal.

Table 1 . Summary report

\section{COMPARISON OF PHOTOGRAMMETRIC POINT CLOUDS}

A TLS point cloud is used as reference in the comparison with the photogrammetric ones, thanks to the favourable conditions of the TLS survey campaign that allowed producing a reliable result. The use of TLS as an independent reference makes the comparisons homogeneous and coherent.

The East side of the tower (in yellow in Figure 4) has been chosen as representative portion for the comparison, because it clearly appears in the majority of the images. The TLS noise measurement on this portion, with a low reflectivity and a distance of $30 \mathrm{~m}$, amounts to about $2 \mathrm{~mm}$ rms.

A first comparison is performed evaluating the point clouds density on a sample of one square meter, located inside that portion of the tower (in red in Figure 4).

Then, the signed distances between two point clouds is computed by $\mathrm{M} 3 \mathrm{C} 2$ (Multiscale Model to Model Cloud Comparison) method implemented in CloudCompare (Lague et al., 2013), as explained in the following.

\subsection{Evaluation of point cloud density}

Each point cloud density has been evaluated in terms of points per $\mathrm{m}^{2}$, considering the red sample shown in Figure 4. The results are reported in Table 2.

While the TLS point cloud has the hugest number of points, the Agisoft PhotoScan $\odot$ one is the less numerous, while the others take values from 1000 to 2000 points, which correspond to a space between points of $0,022-0,032 \mathrm{~m}$. 


\begin{tabular}{|c|c|}
\hline Point cloud & Points per $\mathbf{~}^{\mathbf{2}}$ \\
\hline TLS & 12202 \\
\hline Agisoft PhotoScan`$\odot$ & 552 \\
\hline Pix4D`C & 1556 \\
\hline ContextCaptureTM & 1976 \\
\hline VisualSFM & 1097 \\
\hline MicMac & 1446 \\
\hline
\end{tabular}

Table 2. Points per square meter in the evaluated sample.

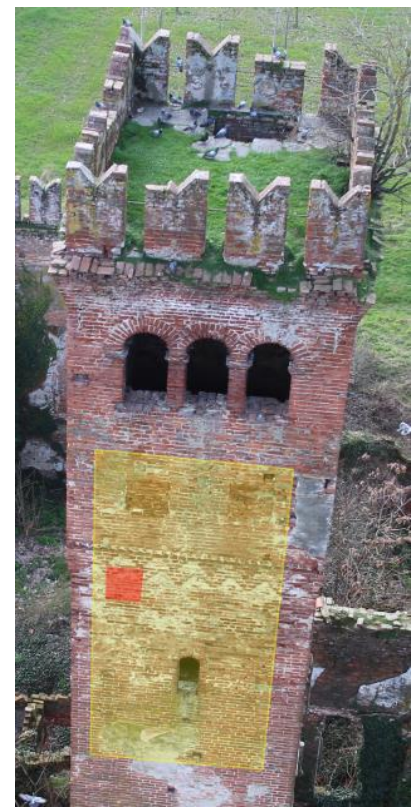

Figure 4. In yellow, the sample used for $\mathrm{M} 3 \mathrm{C} 2$ comparison; in red the sample of a square meter, used to compute the density.

\subsection{M3C2 algorithm application}

$\mathrm{M} 3 \mathrm{C} 2$ plugin is intended to compute signed distances between two point clouds. The $\mathrm{M} 3 \mathrm{C} 2$ algorithm has been carried out using the following settings: the TLS point cloud has been used as reference cloud (Cloud\#1), without applying any subsample, i.e. the core points, on which the computation is performed, are all the points in the cloud; the preferred orientation of point cloud normals has been set on " $+\mathrm{X}$ ", considering the East side of the tower almost parallel to $\mathrm{Y}$ axis. In the output section, the projection of the core points is done keeping original positions; in this way, a new cloud is generated, containing the differences between the tested point clouds.

Once the M3C2 algorithm has been applied, the new cloud has been analysed with the support of the scalar fields (SF) display parameters tool, which allows customising the point cloud visualization according to the most suitable legend. The distribution of the differences has been represented with a Gaussian distribution. The tails have been cut off and the evaluated range has been set from -0.1 to $+0.1 \mathrm{~m}$.

The Gaussian distributions concerning the comparison between each analysed software and TLS are reported in Figure 5, while in Table 3 are stored the mean and the standard deviation.

All the solutions, except MicMac, show a bias with respect to the TLS point cloud: about $+0.01 \mathrm{~m}$ for Agisoft PhotoScan $\odot$ and ContextCapture ${ }^{\mathrm{TM}},+0.015 \mathrm{~m}$ for Pix4DC), and $-0.02 \mathrm{~m}$ for VisualSFM. This could be connected with the RF. In fact the maximum observed shift is approximately twice the GSD.



Figure 5. Results of M3C2 comparisons.

\begin{tabular}{|c|c|c|}
\hline & $\begin{array}{c}\text { Mean } \\
(\mathbf{m})\end{array}$ & $\begin{array}{c}\text { Std } \\
(\mathbf{m})\end{array}$ \\
\hline Agisoft PhotoScan $\odot$ & 0.012 & 0.010 \\
\hline Pix4D $\odot$ & 0.015 & 0.010 \\
\hline ContextCaptureTM $^{\mathrm{TM}}$ & 0.010 & 0.015 \\
\hline VisualSFM & -0.019 & 0.007 \\
\hline MicMac & 0.001 & 0.007 \\
\hline
\end{tabular}

Table 3. Results of M3C2 comparisons in terms of mean and standard deviation.

Remember that: the dense clouds of Agisoft PhotoScan $\odot$ and MicMac have been georeferenced using the GCPs picking in the software themselves; Pix4D( $\odot$ cloud has been referenced in UTM, because the software doesn't work easily in a local RF, and then a roto-translation has been applied, by giving the new coordinates of the GCPs; ContextCapture ${ }^{\mathrm{TM}}$ and VisualSFM clouds have been aligned (roto-translation and scale) by means of CloudCompare.

If the objective is the survey of the only structure in a relative system, as in this case, the bias is not significant. On the other hand, if the building must be seen in a global RF, this error has to be taken into account and evaluated in the light of the representation scale needed.

Nevertheless, the comparisons highlight a good behaviour for all the examined software, also inferable from the low values of standard deviation, included in the range of $0.007-0.015 \mathrm{~m}$.

In Errore. L'origine riferimento non è stata trovata.,Errore. L'origine riferimento non è stata trovata. andFigure the maps of the M3C2 distances, obtained comparing TLS with all the single clouds, are shown. In general, the worst portions are located right by the holes of the masonry and the crenelation (located around 3/4 of the tower top), because of the difficulty of their reconstruction by the photogrammetric software.

In cases of VisualSFM and MicMac, according to the lower standard deviation, the distribution is more homogeneous than other software. The maps related to Agisoft PhotoScan $($ and Pix4D(C) are characterized by a "diffuse dirt", while and ContextCapture ${ }^{\mathrm{TM}}$ one enhances localized areas with higher standard deviations, mainly around the crenelation. 

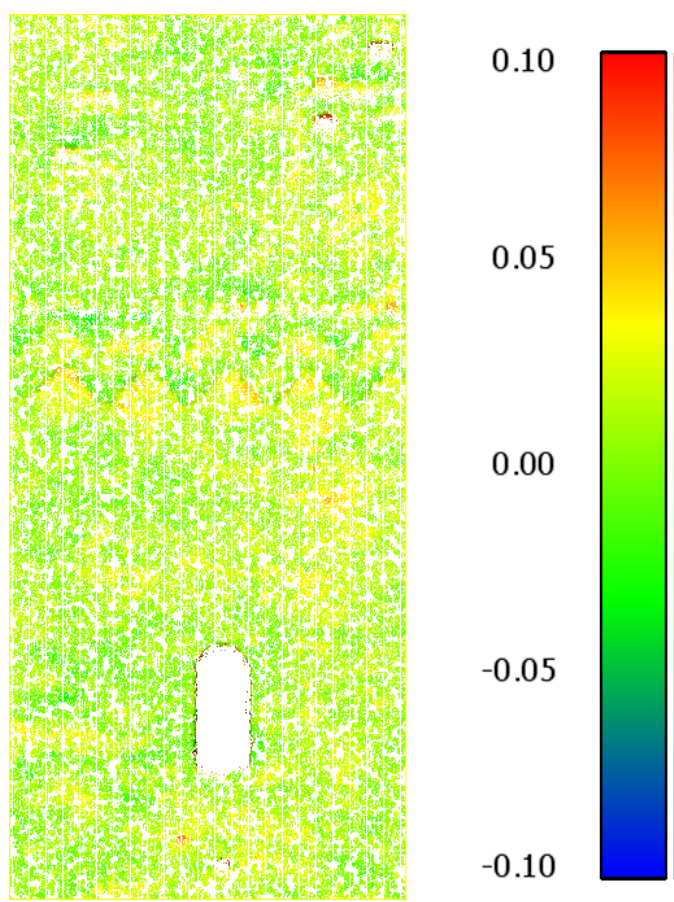

Figure 6. Map of the M3C2 distances between TLS and Agisoft PhotoScan $\odot$
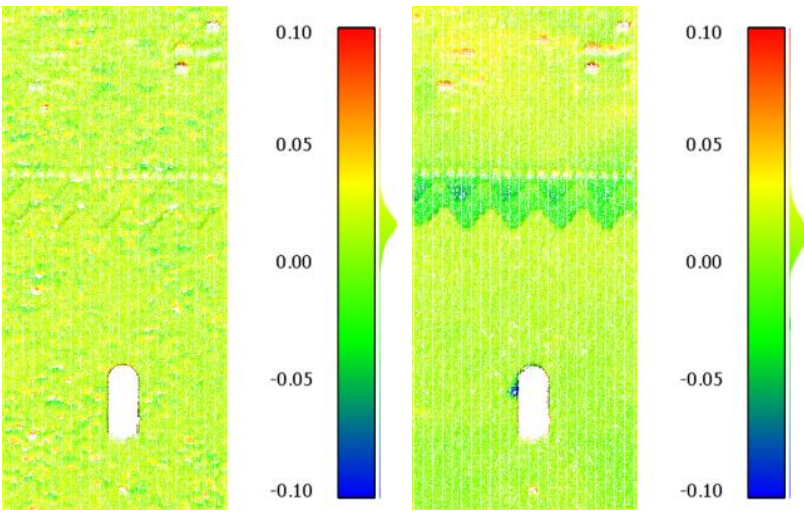

Figure 7. Map of the M3C2 distances between TLS and Pix4DC (on the left) and ContextCapture ${ }^{\mathrm{TM}}$ (on the right); the scale bar is shown in Figure 6
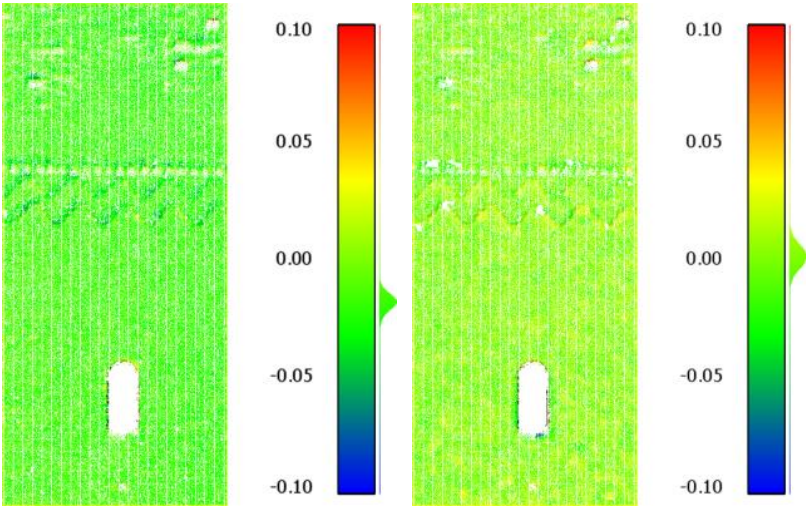

Figure 8. Map of the M3C2 distances between TLS and VisualSFM (on the left) and MicMac (on the right); the scale bar is shown in Figure 6

\section{CONCLUSIONS}

The analysis performed have shown strengths and weaknesses of the tested software. Considering commercial and OS, the strength of the former group is of course the user-friendliness, thanks to the graphic interface and the pre-set with default options. Instead, the strength of the latter group is a rigorous approach, as inferable from the lower standard deviations shown by diagrams.

In most cases, the workflow is complete, with the exception of insight3d, excluded by the point clouds comparison, and VisualSFM, that could not directly perform mesh and orthophotos. The interoperability have been a mark against several software, which could export outputs typically using only PLY or LAS format; anyway, these are two of the most common and diffused file formats.

Only one case is remarkable in terms of time, i.e. ContextCapture ${ }^{\mathrm{TM}}$, which perform a medium dense cloud just in 20 minutes.

Excluding insight $3 \mathrm{~d}$, all the other software offer the possibility to pick GCPs, in a way more or less easy. Moreover, they guarantee the possibility to integrate several datasets of images, taken by different points of view and eventually with different focal distances, too. However, in Pix4D the separation of the images in chunks is required.

The analysis of produced point clouds highlights a good quality for all the examined software.

Concerning the user communities, they are especially useful for OS software, sharing tutorials and documentation in order to help both the developers in the support activities and the users in the tools knowledge deepening. The owners of commercial software typically provide these instruments directly submitting video and PDF files on their official web sites and guaranteeing a support via email or forms.

Lastly, the cost is certainly an important parameter; thanks to the trial version, available for all the commercial software examined, each user could evaluate what is the better solution with respect to his own necessities.

As future purpose, the authors will follow the development of a recent free and OS software, i.e. OpenDroneMap (OpenDroneMap, 2018); this is a toolkit for processing aerial drone imagery, available for Ubuntu, using docker or via web application.

In view of the above, the final aim of the authors is not to give a value judgment about the software or to suggest the use of a specific one, a priori. The objective is to analyse the ease-ofuse, the pros and cons of each software, in order to make the users approach more conscious.

\section{ACKNOWLEDGEMENTS}

The starting point of the tests performed on the Castle of Casalbagliano has been represented by the Master Degree thesis of one of the authors.

A special thanks for the provided support goes to:

- Comune di Alessandria, in particular Arch. Marco Genovese and Geom. Gianfranco Ferraris, for their availability;

- Soprintendenza Belle Arti e Paesaggio della Provincia di Alessandria, in particular Arch. Luigi Pedrini and Dott. Valentina Uras;

- The co-supervisors of the thesis of one of the authors, Eng. Serena Cattari and Arch. Rita Vecchiattini, respectively at DICCA and DAD Departments at the Genoa University; 
- The co-authors of the previous work, Arch. Roberta Fagandini, PhD Eng. Diana Pagliari, Prof. Livio Pinto.

\section{REFERENCES}

Agisoft PhotoScan $\odot, \quad 2018$, http://www.agisoft.com/ (access on $6^{\text {th }}$ April 2018)

Alidoost, F. and Arefi, H., 2017. Comparison of UASbased Photogrammetry software for 3D point cloud generation: a survey over a historical site, ISPRF Ann. Photogramm. Remote Sens. Spatial Inf. Sci., IV-4/W4, 5561, https://doi.org/10.5194/isprs-annals-IV-4-W4-55-2017

Burns, J. H. R. and Delparte, D., 2017. Comparison of commercial Structure-From-Motion Photogrammetry software used for underwater three-dimensional modelling of coral reef environments, Int. Arch. Photogramm. Remote Sens. Spatial Inf. Sci., XLII-2/W3, 127-131, https://doi.org/10.5194/isprs-archives-XLII-2-W3-1272017

CloudCompare, 2018, http://cloudcompare.org/ (access on $6^{\text {th }}$ April 2018)

ContextCapture ${ }^{\mathrm{TM}}, \quad 2018, \quad$ https://www.bentley.com/it (access on $6^{\text {th }}$ April 2018)

Fagandini, R., Federici, B., Ferrando, I., Gagliolo, S., Pagliari, D., Passoni D., Pinto, L., Rossi, L., Sguerso, D., 2017. Evaluation of the Laser Response of Leica Nova Multistation MS60 for 3D Modelling and Structural Monitoring. In International Conference on Computational Science and Its Applications, pp. 93-104

Gabara, G., Sawicki, P., 2017. Study on 3D Point Clouds Accuracy of Elongated Object Reconstruction in Close Range - Comparison of Different Software, 10th International Conference Environmental Engineering, https://doi.org/10.3846/enviro.2017.188

Gagliolo, S., Fagandini, R., Federici, B., Ferrando, I., Passoni, D., Pagliari, D., Pinto, L., Sguerso, D., 2017. Use of UAS for the conservation of historical buildings in case of emergencies. International Archives of the Photogrammetry, Remote Sensing and Spatial Information Sciences, Vol. XLII-5/W1, p. 81-88.

Gini, R., Pagliari, D., Passoni, D., Pinto, L., Sona, G., and Dosso, P., 2013. UAV Photogrammetry: block triangulation comparisons. Int. Arch. Photogramm. Remote Sens. Spatial Inf. Sci., XL-1/W2, 157-162, https://doi.org/10.5194/isprsarchives-XL-1-W2-157-2013

Haala, N., 2013. The Landscape of Dense Image Matching Algorithms. In Photogrammetric Week 13; Fritsch, D., Ed.; Wichmann: Stuttgart, Germany, 2013; pp. 271-284.

Haala, N. and Cavegn, S., 2016. High density aerial image matching: state-of-the-art and future prospects, Int. Arch. Photogramm. Remote Sens. Spatial Inf. Sci., XLI-B4, 625 630, https://doi.org/10.5194/isprs-archives-XLI-B4-6252016 insight3d, 2018, http://insight3d.sourceforge.net/ (access on $6^{\text {th }}$ April 2018)

Lague, D., Brodu, N., Leroux, J., 2013. Accurate 3D comparison of complex topography with terrestrial laser scanner: application to the Rangitikei canyon (N-Z). ISPRS Journal of Photogrammetry and Remote Sensing 82, pp. $10-26$

MicMac, 2018, http://micmac.ensg.eu/ (access on $6^{\text {th }}$ April 2018)

Niederheiser, R., Mokroš, M., Lange, J., Petschko, H., Prasicek, G., and Elberink, S. O., 2016. Deriving 3D point clouds from terrestrial photographs - comparison of different sensors and software, Int. Arch. Photogramm. Remote Sens. Spatial Inf. Sci., XLI-B5, 685-692, https://doi.org/10.5194/isprs-archives-XLI-B5-685-2016

OpenDroneMap, 2018, http://opendronemap.org/ (access on $6^{\text {th }}$ April 2018)

Pavelka, K., Řezníček, J., Bílá, Z., Prunarová, L., 2013. Non Expensive 3D Documentation and Modelling of Historical Object and Archaeological Artefacts by Using Close Range Photogrammetry, Geoinformatics FCE CTU 10https://doi.org/10.14311/gi.10.5

Pix4D, 2018, https://pix4d.com/ (access on 6 ${ }^{\text {th }}$ April 2018)

Remondino, F., Spera, M. G., Nocerino, E., Menna, F., Nex, F., 2014. State of the art in high density image matching, The Photogrammetric record, Volume 29, Issue 146, June 2014, pp. 144-166, DOI: 10.1111/phor.12063

Schöning J., Heidemann G., 2015. Evaluation of Multiview 3D Reconstruction Software. In: Azzopardi G., Petkov N. (eds) Computer Analysis of Images and Patterns. CAIP 2015. Lecture Notes in Computer Science, vol 9257. Springer, Cham, https://doi.org/10.1007/978-3319-23117-4_39

Svensk, J., 2017. Evaluation of aerial image stereo matching methods for forest variable estimation, Master of Science Thesis in Computer Vision Department of Electrical Engineering, Linköping University

VisualSFM, 2018, http://ccwu.me/vsfm/ (access on $6^{\text {th }}$ April 2018)

Wojtas, A. M., 2010. Off-the-shelf close-range photogrammetric software for cultural heritage documentation at Stonehenge, International Archives of Photogrammetry, Remote Sensing and Spatial Information Sciences, Vol. XXXVIII, Part 5. Commission V Symposium, Newcastle upon Tyne, UK 